\section{MS21 P06}

Structure Of $\left[\left(\mathrm{Hoc}_{2} \mathbf{h}_{4}\right)_{3} n h\right]_{4} \mathbf{p}_{4} \mathbf{o}_{12}$ R. Nahouane ${ }^{\mathrm{a}}$, E. H. Soumhi $^{\mathrm{a}}$, I. Saadoune ${ }^{\mathrm{a}}$ and A. Driss ${ }^{\mathrm{b}}$

${ }^{a}$ Equipe Chimie des Matériaux et de l'Environnement, LP2E2M, FST Marrakech, Université Cadi Ayyad, Morocco ; ${ }^{b}$ Faculté des Sciences de Tunis, Laboratoire des Matériaux et de Cristallochimie, Tunisia

Organic-cation phosphates have been intensively studied due to their many uses in various fields such as protonic conductors and nonlinear optics [1-2]. Most organic-cation phosphates are formed essentially in the way of H-bond between phosphoric anions and organic groups which contain generally donor centers [3-4]. In the present paper, we report detailed structural investigation of a new organic-cation cyclotetraphosphate obtained by using a tertiary amine: $\left(\mathrm{HO}-\mathrm{CH}_{2}-\mathrm{CH}_{2}\right)_{3} \mathrm{~N}$. The compound was prepared by neutralization of $\mathrm{H}_{4} \mathrm{P}_{4} \mathrm{O}_{12}$ with organic amine in a 4:1 molar ratio. The $\mathrm{H}_{4} \mathrm{P}_{4} \mathrm{O}_{12}$ solution was prepared using an aqueous solution of $\mathrm{Na}_{4} \mathrm{P}_{4} \mathrm{O}_{12}$ and an ionexchange resin (Amberlite IR-120). Colorless single crystals appeared after evaporation of the solution at room temperature for a few days. The compound has been studied by single crystal X-ray diffraction. The crystals belong to space group $\mathrm{P} 2 / \mathrm{n}$ with unit cell parameters: $\mathrm{a}=9.945(2) \AA, \quad \mathrm{b}=14.591(3) \AA, \quad \mathrm{c}=14.428(3) \AA \quad$ and $\beta=101.12(2)^{\circ}$. The asymmetric unit of the title compound consists of two triethanolammonium cations and two $\mathrm{PO}_{4}$ tetrahedra which form one half of a $\mathrm{P}_{4} \mathrm{O}_{12}$ cycle built around an inversion centre. All bond distance and angle values deduced from the refinement are in good agreement with those observed in similar condensed phosphates [3-4]. From a general point a view, the structure of this phosphate could be described as a succession of two types of layers parallel to $\left(\begin{array}{lll}-1 & 0 & 1\end{array}\right)$ plane. The first one formed simultaneously by the $\left(\mathrm{P}_{4} \mathrm{O}_{12}\right)^{4-}$ anions and the second organic cation (N2). The second layer is formed only by the first organic cation (N1). The hydrogen bonds contribute significantly to stabilizing the structure of this salt.

[1] Casiola M. et al., 1986, Solid State Ionics, 22, 127-133.

[2] Kita Y. et al., 1995, Nippon Kagaku Haishi, 12, 971-980.

[3] Nahouane R. et al., 2005, Acta cryst. E61, o2850-o2852.

[4] Soumhi E.H. et al., 2006, Acta cryst. E62, o212-o214

Acknowledgements: This work has been supported by the Morocco-Tunisia scientific cooperation

\section{MS21 P07}

Structural Changes upon Lithium insertion in $\mathbf{C o}_{0,5} \mathbf{T i O P O}_{4}$ Rachid Essehlia, b Brahim El Bali ${ }^{\text {a }}$, Helmut Ehrenberg ${ }^{\mathrm{b}, \mathrm{c}}$, Ingrid Svoboda ${ }^{\mathrm{b}}$, Kristian. Nikolowski ${ }^{\mathrm{b}}$, Natalia Bramnik ${ }^{\mathrm{b}}$ and Hartmut Fuess ${ }^{\mathrm{b} a}$ Laboratory of
Mineral Solid and Analytical Chemistry "LMSAC" Department of Chemistry, Faculty of Sciences, University Mohamed I Po. Box 624, 60000 Oujda, Morocco ${ }^{\mathrm{b}}$ Institute for Materials Science, Darmstadt University of Technology, Petersenstrasse 23, D-64287 Darmstadt , Germany ${ }^{\mathrm{C}}$ Leibniz Institute for Solid State and Materials Research Dresden (IFW), Helmholtzstr. 20, D-01069 Dresden, Germany E-mail: essehli rachid@yahoo.fr

\section{Keywords: Oxyphosphate, Rietveld Refinment, electrodes for lithium batteries}

Recently, we discovered a new class of lithium insertion compounds by investigating the ternary diagram of (MO$\left.\mathrm{TiO}_{2}-\mathrm{P}_{2} \mathrm{O}_{5}\right)$. These oxyphosphates $\mathrm{M}_{0.5} \mathrm{TiOPO}_{4}(\mathrm{M}=$ $\mathrm{Co}^{2+}, \mathrm{Ni}^{2+}, \mathrm{Cr}^{2+} \ldots$ ) could act as electrodes for lithium batteries that provide high energy density. Up to three lithium atoms could be inserted per crystalline cell generating thus an initial practical capacity of $434 \mathrm{mAh} / \mathrm{g}$. The structural investigation of the phase transformations occurring upon lithium insertion in $\mathrm{Co}_{0.5} \mathrm{TiOPO}_{4}$, for the two ex-situ diffraction pattern were taken for the composition of and $\mathrm{Li}_{3} \mathrm{Co}_{0,5} \mathrm{TiOPO}_{4}$ For $\mathrm{Li}_{3} \mathrm{Co}_{0,5} \mathrm{Ti}^{\mathrm{III}} \mathrm{OPO}_{4}$ the amorphization of the sample was observed. The $\mathrm{LiCo}_{0,5} \mathrm{TiOPO}_{4}$ structure has been determined from conventional X-ray powder diffraction data, by Rietveld method in $\mathrm{P} 2{ }_{1} / \mathrm{c}$ space group. The cell parameters are: $[\mathrm{a}=7.3385(1) \AA, \mathrm{b}=7.6066(1) \AA, \mathrm{c}=$ $7.5507(1) \AA, \beta=118.75(2)^{\circ}$ and $\left.Z=4\right]$. This structure can be described as a 3-dimensional network of $\left[\mathrm{TiO}_{6}\right]$-, $\left[\mathrm{LiO}_{6}\right]-$ and $\left[\mathrm{CoO}_{6}\right]$-octahedra and $\left[\mathrm{PO}_{4}\right]$ tetrahedra. $\mathrm{LiO}_{6}$ and $\mathrm{CoO}_{6}$ octahedra share edges and form chains running parallel to the a axis. Each $\mathrm{PO}_{4}$ tetrahedra shares 2 oxygen atoms with two $\mathrm{TiO}_{6}$ consecutive octahedra of one chain and one oxygen atom with a neighboring parallel chain of the sheet. Links of sheets by the remaining oxygen atom of phosphate tetrahedron lead to a $\left[\mathrm{TiOPO}_{4}\right]^{\mathrm{n}-}$ threedimensional framework. Titanium atoms are displaced from the geometrical center of the octahedra resulting in long (2.303(1) $\AA$ ) Ti-O(5) and short (1.613(1) $\AA$ ) Ti-O(3). The four remaining are between $1.839(1)$ and 2.149(1) $\AA$ distances. In one chain the off-center displacement of $\mathrm{Ti}$ atoms induces creation of electric moments. As the space groupe $\mathrm{P} 2{ }_{1} / \mathrm{c}$ is centrosymmetric, there is compensation of antiparallel moments of an adjacent chain, so $\mathrm{LiCo}_{0.5} \mathrm{Ti}^{\mathrm{III}} \mathrm{OPO}_{4}$ is antiferroelectric

Acknowledgements

R. Essehli thanks the Deutscher Akademischer Austausch-Dienst (DAAD) for the support in enabling the visit to Darmstadt (Germany).General support of the NoE FAME of the European Union is gratefully acknowledged 